
\title{
3 Research Square \\ Facilitators and Barriers Return to Work in Working People with Serious Mental IIIness: A Qualitative Study
}

\section{Maryam Maddineshat}

Hamedan University of Medical Sciences

\section{Efat Sadeghian}

Hamedan University of Medical Sciences

\section{Ali Ghaleiha}

Hamedan University of Medical Sciences

\section{Mitra Khalafbeigi}

Iran University of Medical Sciences

Fatemeh Cheraghi ( $\nabla$ neshat.maryam1357@gmail.com )

Hamedan University of Medical Sciences

\section{Research Article}

Keywords: Return to Work, Back to Work, Severe Mental Disorder, Serious Mental Illness, Sick Leave, Qualitative Research

Posted Date: April 8th, 2021

DOI: https://doi.org/10.21203/rs.3.rs-382274/v1

License: (1) This work is licensed under a Creative Commons Attribution 4.0 International License. Read Full License

Version of Record: A version of this preprint was published at Indian Journal of Psychological Medicine on March 1st, 2022. See the published version at https://doi.org/10.1177/02537176221074730. 


\section{Abstract}

Background: Many factors affect return to work (RTW) in employees and workers (hereinafter referred to as working people) with serious mental illness (SMI). Identifying these factors can prevent long-term sick leave absence and work disability.

Aim: The current study was conducted to identify facilitators and barriers RTW in working people with SMI admitted to a psychiatric hospital and clinic affiliated with the Hamadan University of Medical Sciences, Iran.

Methods: A qualitative study was conducted in 2020 on 27 participants with SMI, families, supervisors, managers, and mental health team members. The participants were selected through purposive sampling. Data were collected using in-depth and semi-structured interviews. A total of 40 interviews were conducted face-to-face and fallow-up by the telephone. The interviews were based on a conventional content analysis approach.

Results: Two main themes emerged, including social support and RTW's challenges. Social support consisted of four main categories: emotional support, information support, instrumental support, and supervisor's flexibility. RTW's challenges consisted of two main categories: personal obstacles and general issues.

Conclusion: We found that two facilitator and barrier factors including social support and RTW's challenges affected the RTW process in working people with SMI. Identifying facilitator and barrier factors gives us comprehensive information to use in RTW programs and developing policies RTW in working people with SMI.

\section{Introduction}

Mental illnesses are also common among people who are working(1). Working people with serious mental illness (SMI) are notably susceptible to sick leave's adverse effects, work disability, losing purpose, and a higher risk of social isolation $(2,3)$. The distance from work increases the risk of unemployment, poverty, and deteriorated mental health conditions. Moreover, all these decrease the chance of returning to work, as having a job increases one's health and social participation and improves their work quality (4).

Over the past two decades, the knowledge has increased about acquiring and maintaining a job in people with SMI. By introducing a wide range of occupational rehabilitation programs, researchers attempt to help these people find and maintain a job. However, return to work (RTW) in working people with SMI has received less attention (4-6). Bejerhom and Areberg (2014) maintained that some people with SMI receive no RTW support program. In these cases, people with SMI tries to RTW without receiving any help (7). Through this process, they might be influenced by their family members' decisions or concerns about discrimination or stigmatization at work. Therefore, many of them refuse to RTW despite sick leave' 
adverse effects $(8,9)$ Notably, there are differences between countries in terms of labor laws, sick leave policies, and support for working people with SMI, which all affect RTW (10).

Notably, RTW is a dynamic process as a result of workers' interactions and the work environment in specific cultural, social, and economic factors. To better understand the RTW process and the RTW program's development, we need more extensive knowledge about factors influencing RTW. Thus, more information is required about families, workplaces, healthcare systems, and society in general $(11,12)$.

Despite the high prevalence of mental illness in working people, there has been no specific RTW study in Iran. As a developing country with unique cultural, social, and economic factors, Iran has its differences with developed countries. Following the international sanctions against Iran, vulnerable and debilitated groups face more challenges in accessing rehabilitation services (13). There is a lack of information about RTW in working people with SMI, and qualitative studies are more efficient in understanding factors affecting RTW (14). Besides, the knowledge obtained from qualitative studies can create new insight into the variant effects of facilitators and barriers. Such knowledge can prevent the risk of long-term sick leave and debilitation in this group of people (2). The current study was conducted to identify facilitators and barriers RTW in working people with SMI admitted to a psychiatric hospital and clinic affiliated with the Hamadan University of Medical Sciences, Iran.

\section{Methods}

\section{Design and study setting}

In this qualitative study, to gain access to the participants' medical history and employment condition, the researchers visited the Farshchian Psychiatric Center (Sina) affiliated with the Hamadan University of Medical Sciences, clinics of the hospital, and psychiatrists' offices. Based on theoretical sampling, other study settings included the participants' workplaces, the Welfare Organization, the Imam Khomeini Relief Foundation, and the Iranian Society Supporting Individuals with Schizophrenia.

\section{Participants}

As a qualitative study, the participants were recruited through purposive sampling with maximum variety. In purposive sampling, the researcher looks for participants with rich experiences about the phenomenon under study who are willing to share their experiences (15). Participants in this study were working people with SMI willing to participate in the study. One inclusion criterion was people with a definite diagnosis of SMI based on DSM5 in their medical history. By definition, SMI refers to mental, behavioral, or emotional disorders creating severe functional disorders that mostly intervene with one or many major life activities. Most cases in this category are schizophrenia, bipolar disorder, schizoaffective, and significant depression disorder $(16,17)$.

Other inclusion criteria were being an adult and conscious, having a job before developing SMI, being discharged from the hospital, being in the recovery phase, having a job at least 28 days continuously, and 
having the ability to communicate and express experiences, feelings, and reactions. Based on the International Labor Organization regulations, which are accepted in Iran, one has a job if they work for at least one hour per week in return for cash or non-cash salary (18). Individuals with alcohol and drug addiction problems or those with mental and developmental disorders were excluded.

The participants included working people with SMI (15 person) with RTW experience who entered the study using purposive sampling. Based on analyzing the study's collected data and obtaining rich information about returning to work(19), other participants, including 3 family members, 1 manager, 2 supervisors, and 6 health care team members. The participants' maximum variety was ensured in terms of age, gender, education level, type of disease, workplace, job condition, RTW length, different worker and employee groups (public and private), experiences, and SMI. After 24 interviews, data saturation was achieved, and the three last interviews yielded no new data. The demographics of the participants are listed in Table 1.

Table 1

Socio-demographic characteristics of participants

\begin{tabular}{|c|c|c|}
\hline \multirow{7}{*}{$\begin{array}{l}\text { Working } \\
\text { people with } \\
\text { SMI }\end{array}$} & Sex & $11 \mathrm{M}, 4 \mathrm{~F}$ \\
\hline & Age(year) & 27 to $51($ Mean $=39.2)$ \\
\hline & $\begin{array}{l}\text { Marital } \\
\text { status }\end{array}$ & Single, Married, Divorced \\
\hline & Education & Primary school to Academia \\
\hline & Diagnosis & Major Depression, Bipolar II, Schizoaffective, Schizophrenia \\
\hline & Occupation & $\begin{array}{l}\text { Employer, Transit Bus Driver, Hairdresser, Military, Teacher, Nurse, } \\
\text { Shopkeeper, Graphic Designers, Miner, Carpet weaver, Cleaning } \\
\text { person, Radiology Technician, Tailor, Bank Manager }\end{array}$ \\
\hline & $\begin{array}{l}\text { Length of } \\
\text { RTW }\end{array}$ & 2 to $12($ Mean $=6.66)$ \\
\hline \multirow{6}{*}{$\begin{array}{l}\text { Other } \\
\text { participants } \\
\text { (related to } \\
\text { working people } \\
\text { with SMI) }\end{array}$} & Sex & $8 \mathrm{~F}, 4 \mathrm{M}$ \\
\hline & Age(year) & 36 to $52($ Mean $=45.25)$ \\
\hline & $\begin{array}{l}\text { Marital } \\
\text { status }\end{array}$ & Married \\
\hline & Education & Primary school to Academia \\
\hline & Occupation & $\begin{array}{l}\text { Housewife, Teacher, Head Nurse, Nurse Manager, Manager in } \\
\text { organization, Psychiatrist, Psychologist, social worker, Nurse, } \\
\text { Manager in welfare organization, Supervisor, Assistant manager } \\
\text { Imam Khomeini Relief Foundation }\end{array}$ \\
\hline & $\begin{array}{l}\text { Relative to } \\
\text { working } \\
\text { people with } \\
\text { SMI }\end{array}$ & Spouse, Mother, Co-worker, Supervisor, Manager \\
\hline
\end{tabular}




\section{Data collection and analysis}

The study was conducted from 9th February 2020 to 20th December 2020. The first author (MM) with the experience of working in psychiatric department checked the participants' medical documents. The third author (AG) as an experienced psychiatrist confirmed the documents. Then, the first author (MM) called the participants and arranged the interviews. The interviews were face-to-face as semi-structured and indepth interviews held in the first researcher's office. The interviews re-read by the research team members and discussed to determine the validity of the interview guideline questions. Two interviews were conducted as a pilot initiative and guide for the questions, which were not included in the analyses.

Each interview started with an open general question. The participants were asked questions like "what caused the facility in your RTW?" and "what caused the delay in your RTW?" Also, Probes were used to encourage participants to elaborate on: " Can you please tell me more about that?"," what's your mean?", and "Can you give me an example?". Also, participants were given the opportunity at the end of the interview to add further information that was not asked them during the interview.

The researcher also took note of her observations as field notes. Each interview lasted 30-45 min. To gain rich information, informal and telephone interviews were also conducted along with formal interviews. A total of 40 interviews were conducted with 27 participants. Interview analysis was carried out while collecting data. By emerging codes and primary concepts, more specific and modified questions were added to the interview guide. Qualitative conventional content analysis was used for data analysis. The researcher transcribed each interview based on Erlingsson \& Brysiewicz's qualitative content analysis approach (20). Semantic units were determined for analyzing the interview scripts followed by open coding (live or interpretive). Three of the researchers repeated the coding process cautiously. The codes were compared and categorized based on similarities and differences to obtain subcategories. The researchers attempted to classify subcategories with the highest homogeneity into one category and to form themes by combining categories. The interviews were analyzed using MAXQD 2018. The four criteria of confirmability, dependability, trustworthiness, and credibility were used to determine data's validity and reliability (21).

In this study, the researchers' long-term engagement, maximum diversity in sample selection, appropriate interaction with participants, integration of information, and checking the data by the participants helped to increase the credibility. The reliability or consistency of the findings was assured by writing memos as soon as possible, using peer reviews, and re-reading the entire data. Confirmability was obtained by avoiding any bias, and reaching agreement on codes and themes by all research team members. To enhance transferability of the data, the entire process of research and the work carried out along the study path were clearly and precisely written to allow others to follow the research path and the characteristics of the study population. Transferability was also assured by providing direct quotes and examples, rich explanations of data, and scientific consultations with expert university professors. When preparing the study report, we used the Consolidated Criteria for Reporting Qualitative Research (COREQ) 
checklist. The research team of this study includes five researchers with backgrounds in Psychiatric Nursing, Psychiatry, and Occupational Therapy, all of whom have previous experiences of qualitative studies.

\section{Findings}

A total of 900 initial codes were extracted and categorized into 32 subcategories and six categories. Eventually, two main themes of social support and RTW's challenges were revealed (Table 2). 
Table 2

Illustration of subcategories, categories, and themes

\begin{tabular}{|c|c|c|}
\hline Theme & Categories & Subcategories \\
\hline \multirow{21}{*}{$\begin{array}{l}\text { Social } \\
\text { Support }\end{array}$} & \multirow{4}{*}{$\begin{array}{l}\text { Emotional } \\
\text { supporting }\end{array}$} & Emotional assistance by family members \\
\hline & & $\begin{array}{l}\text { Tolerating working people's poor mental health status by family } \\
\text { members }\end{array}$ \\
\hline & & Emotional assistance by co-workers \\
\hline & & Emotional assistance by friends \\
\hline & \multirow{4}{*}{$\begin{array}{l}\text { Informational } \\
\text { supporting }\end{array}$} & Receiving advice from family members \\
\hline & & Receiving guidance from the supervisor \\
\hline & & Receiving advice from the psychiatrist \\
\hline & & Receiving education about mental illness from healthcare teams \\
\hline & \multirow{9}{*}{$\begin{array}{l}\text { Instrumental } \\
\text { supporting }\end{array}$} & Receiving financial aid from family members \\
\hline & & Offering assistance in tasks by family members \\
\hline & & Offering assistance in tasks by co-workers \\
\hline & & Offering assistance in tasks by the supervisor \\
\hline & & Receiving financial aid from the Welfare Institution \\
\hline & & Having close colleagues at work \\
\hline & & $\begin{array}{l}\text { Offering assistance to take necessary certificates to RTW by the } \\
\text { psychiatrist }\end{array}$ \\
\hline & & Improving the public' attitude toward mental illness by education \\
\hline & & $\begin{array}{l}\text { Initiating and drafting legislation by the government to protect the } \\
\text { rights of people with mental illness }\end{array}$ \\
\hline & \multirow{4}{*}{$\begin{array}{l}\text { Supervisor's } \\
\text { flexibility }\end{array}$} & Agreeing to RTW by supervisor \\
\hline & & Making balance in work schedule by supervisor \\
\hline & & Suggesting fit work by supervisor \\
\hline & & Making balance in rules for RTW by supervisor \\
\hline \multirow{4}{*}{$\begin{array}{l}\text { RTW's } \\
\text { Challenges }\end{array}$} & \multirow{4}{*}{$\begin{array}{l}\text { Personal } \\
\text { obstacles }\end{array}$} & Residual symptoms of mental illness \\
\hline & & Having inappropriate personal traits for working \\
\hline & & Low motivation to RTW \\
\hline & & Low confidence to RTW \\
\hline
\end{tabular}




\begin{tabular}{|c|c|c|}
\hline Theme & Categories & Subcategories \\
\hline & & Worrying about keeping mental health at work \\
\hline & & Worrying about work conditions \\
\hline & \multirow[t]{5}{*}{ Public issues } & The low social support of people with mental illness to RTW \\
\hline & & $\begin{array}{l}\text { The poor attitudes of some organizations toward people with } \\
\text { mental illness }\end{array}$ \\
\hline & & $\begin{array}{l}\text { The Welfare Organizations problems to help people with mental } \\
\text { illness to RTW }\end{array}$ \\
\hline & & The poor government support of mental health teams \\
\hline & & The country's financial sanctions \\
\hline
\end{tabular}

\section{Theme 1: Social support}

To identify the facilitators and barriers, the participants mentioned different support approaches that affected their RTW. This theme had four main categories: emotional support, information support, instrumental support, and supervisor flexibility.

\section{Category 1.1: Emotional support}

The participants mentioned that they received support from families, friends, and co-workers. For instance, parents would lower tension among family members and create a more peaceful environment for people with SMI. Moreover, spouses would motivate people with SMI to RTW by giving hope and coping with the patients' low spiritual condition. A working participant said: "... My mother says that I should RTW; she says that I forget about the mental illness when I am talking to others; she tries to motivate me..." (P.3). In addition to the families, co-workers and friends can also be supportive. One of the working participants added: "...My co-workers knew about my mental illness and would try to help me by telling me to control myself, forget about the troubles, and things like that..." (P1).

\section{Category 1.2: Informational support}

This category reflected the support that family members, supervisors, and psychiatrists would advise working people with SMI to decide RTW. For instance, one of the participants' spouses advises her husband on how to talk to his supervisor to convince him to RTW. One of the participants' supervisors talked about her recommendations, "... That nurse called me (supervisor) after her recovery and said that he did not want to come to work... but she wanted to keep her work. I said if you do not have a shift, the nurse manager will consider absenteeism. He asked me for helping. I told him to send me her sick leave documents and I will show them to the nurse manager..." (P19). Also, the participants noted that they 
would consult their psychiatrist about RTW and the psychiatrist usually talks about occupational stresses and that they should decrease the workload.

\section{Category 1.3: Instrumental support}

A major part of social support was in the instrumental support category. Financial support by family members or taking a loan from the Welfare Organization was notable. Self-employed people usually need financial support to RTW. For instance, one of the participants' mother who had a supermarket noted: "... my boy used to work with his father, and after the mental illness, we helped him to open a new store. He also asked for a loan of RIs.100.000.000 from Imam Khomeini Relief Foundation..." (P18). Another type of instrumental support was the assistance offered to working people with SMI by co-workers and supervisors. A supervisor may help working people with SMI maintain their jobs during sick leave, or coworkers might undertake their co-worker's tasks during their absence. Moreover, psychiatrists also help these individuals by issuing health or sick leave certificates. Some of the participants mentioned that having their relatives at work facilitated their RTW. For instance, they lobbied with the supervisor to facilitate the RTW of their relatives and the supervisor usually accepted their request. One of the participants' supervisors stated:

"His psychologists (P6-nurse) strongly supported him using his position in the organization. He called me frequently and asked us to let him back... I could not say No..." (P20).

Healthcare teams, organizations, and the government support the RTW of people with SMI by improving the public culture about mental illness and alleviating the stigma. For instance, a psychiatrist explains that educational programs should be developed to change the attitudes of family members, especially spouses, toward people with SMI to reduce the stigma of mental illness. Healthcare systems and organizations should provide such educations. The government has also approved regulations for supporting people with SMI. These regulations extend premium exception for employers who recruit people with SMI. About SMI employees, an organization manager stated: "... An order has come from the ministry and in it, managers are asked to support SMI employees ... therefore, I have recruited a psychologist to help these employees..." (P22).

\section{Category 1.4: Supervisor's flexibility}

The supervisor's flexibility was another social support for the participants that facilitated their RTW. A group of working participants expected to RTW after proving that they regained their mental health. Some working participants' characteristics made the supervisor accept such requests, such as long work history, a positive work record, and awareness about the participants' poor living conditions. These considerations convince supervisors to accept RTW requests, adjust the work schedule, and prepare a suitable mental condition for working. One of the participants added: "... after recovery, I asked the supervisor for RTW... given my long and positive work record, my request was accepted and I back to work as a substitution teacher to fill the places of those who miss a class. I also receive the full salary, despite less work and a better work condition... I spend most of my time at home..." (P5). 


\section{Theme 2: RTW's challenges}

RTW's challenges were another factor experienced by the participants in the RTW process. This theme included two categories of personal obstacles and public issues.

\section{Category 2.1: Personal obstacles}

Some of the participants mentioned that they faced personal obstacles in the RTW process, which restricted or delayed their RTW. One of the participants explained that while preparing to RTW, he was still feeling the symptoms. "... As military personnel, I have to RTW after sick leave period; however, I do not feel that I like it..., it is a real bore" (P4).

Some of the participants noted that they had particular characteristics that were not suitable for work. For instance, they were not that mind sharp at work, preferred isolation, were shy, preferred seclusion, and did similar things. These characteristics affected their chance of RTW and delayed it. Some of the participants were continuously worried that the employer might find out about their mental problems. They felt worried about whether they were capable enough to do their tasks at work, and that they may be blamed by their employers if they did not have enough ability; these concerns decreased their selfconfidence. They were also worried about preserving their mental health at work including the fear of recurrence of the mental disease at work, inability to control the residual symptoms of the disease, and the medication side effects. All these experiences and many other factors created a dark image of RTW in their mind, causing them to lose motivation to RTW. One of the participants explained, “... the Previous failure sometimes makes one not feel like going back to work ..." (P11).

\section{Category 2.2: Public issues}

Like other society members, the participants had their general and more prominent public or social problems. As a result, they may become hesitant to RTW and delay it. While some of the participants received financial support from their families and the Welfare Organization, some others struggled with financial problems while attempting to RTW. Furthermore, the country's poor economic condition due to sanctions and the COVID-19 pandemic intensified such financial problems. One of the working participants' spouses explained: "...My husband can handle the work, but financial problems do not allow him to work fulltime. When the US dollar price surges high suddenly, he cannot supply the materials he needs for work. Therefore, he cannot accept orders as much because he cannot supply the material...." (p16).

The participants also had social problems that restricted their RTW. For instance, some organizations had negative attitudes toward working people with SMI or could not decrease the workload due to inadequate workforce. Moreover, the Welfare Organization had its limitations and complained about the lack of adequate public funding or the large number of applicants. It claimed that it could not cover all applicants, which made applicants dissatisfied. There were also extensive bureaucratic structures like bank regulations that prevented an easy and smooth RTW. One of the participants added: "... I went to 
Welfare Org. after recovery, but they had closed their workshop because of COVID-19 and there was no job for me. I applied for a loan to buy a small carpet workshop. They referred me to a bank, and the bank told me that I need an officially employed public worker as guarantor. I have nobody for this and I do not know what to do..." (P10).

We designed a conceptual model to clarify the obtained themes, categories, and subcategories (Fig. 1).

\section{Discussion}

The current study was conducted to determine facilitators and barriers RTW in working people with SMI admitted to a psychiatric hospital and clinic affiliated with the Hamadan University of Medical Sciences, Iran. As the findings showed, two facilitator and barrier factors, namely "social support" and "RTW's challenges," affected RTW in working people with SMI. The findings showed that two factors affected working people with SMI at different levels, including personal, family, work, and society levels. Some of these factors were supportive and facilitating factors, while others created challenges to RTW. In line with this study's results, Habtamu et al. (2015) showed that a broad factors including a range of clinical symptoms and non-clinical symptom factors (e.g., supportive factors and socioeconomic conditions of society) affected RTW in working people with SMI (22).

In the present study, facilitator's factors influencing RTW in working people with SMI included the support they received from families, friends, co-workers, and supervisors. However, the emotional support and encouragement of working people alone are not enough. They need to receive guidance, advice, and recommendations to RTW, and most importantly, all people related to them need to help practically. Dunn et al. showed that workers with SMI needed at least one supporter to RTW, given that the mental illness lowered their performance at work. Employers, co-workers, families, and mental health team members are not the same for all working people. However, these supports create hope and motivation in working people with SMI to improve their skills, self-confidence, and capabilities to find jobs suitable for them. When working people with SMI demonstrate that they are eager to work, they prepare the context for receiving supports (23).

This study showed that RTW in the participants was not straightforward and linear; employers and managers and, in general, the public did not want working people with SMI back to work, even if they expressed willingness to RTW. The path, in practice, was full of challenges, including personal and public troubles. Personal troubles were related to the participants' conditions in their environment, while public issues affected the whole society, and not only the working participants.

Ebueny et al. explained that people with mental illnesses dealt with challenges affected by many factors. These factors are in constant flux and dynamic interaction with each other. Depending on positive or negative factors in the local environment, people with SMI might be able to RTW and maintain their job (24). Some of them able to RTW might experience social supports in their path. In contrast, others might face inflexible supervisors, the lack of coordination in organizations, and unclear laws. There is an ambiguity in regulations and supportive attitudes so that not all stakeholders have identical performance 
to support workers and workers themselves need to deal with challenges (25). Evidence has shown that people with SMI, especially in countries with low- and moderate-income levels, deal with broad and multiaspect political, economic, social, and cultural limitations. Negative reactions and exaggerated fears in families, supervisors, co-workers, and society about mental illnesses create agony for people with such diseases and trouble society. Since society is forced to give up on these workforces' benefits, this highlights the necessity of social support and cultural works for people with SMI at different individual, family, work, and society levels. People with SMI need a combination of supportive factors $(22,26-28)$.

A few limitations are notable in this study. This qualitative study was carried out based on available samples, as the transferability of ideas was more critical than their generalizability. The highest diversity in the demographics and RTW length was ensured to widen factors' variation. Moreover, supplementary interviews were conducted with families, employers, and mental health team members. Despite the limitations, the study developed a background for further studies by identifying fundamental factors. As a result, the study prepared the background for interventions to improve the RTW process in people with SMI.

\section{Conclusion}

We found that two facilitator and barrier factors including social support and RTW's challenges affected the RTW process in working people with SMI. Social support proceeded RTW, while RTW's challenges restricted or delayed RTW in working people with SMI. Identifying facilitators and barriers gives us comprehensive information to use in RTW programs and developing policies RTW in working people with SMI.

\section{Declarations}

\section{Ethics approval and consent to participate}

The study is part of a more comprehensive study for a Psychiatric Nursing Ph.D. dissertation approved by the Ethics Committee and Research Council of Technology and Technology, the Hamadan University of Medical Sciences (IR.UMSHA.REC.1399.504). All methods were carried out following the institutional guidelines and regulations and conforming to the ethical standards of the declaration of Helsinki. All the participants were informed about the study's objectives and stages. Participation was entirely voluntary. The participant signed an informed consent form for audio recording the interviews. The participants could leave at any stage of the study.

\section{Consent for publication}

Not applicable in this study.

\section{Availability of data and materials}


The datasets generated and/or analyzed during the current study are not publicly available due the raw data contains information that could compromise the participant's privacy, but are available from the corresponding author on reasonable request.

\section{Competing interests}

The authors declare that they have no competing interests.

\section{Funding}

This project has received funding from the Vice-Chancellor for Research of Hamadan University of Medical Sciences2020 research (Grant agreement: No. 9906254144).

\section{Authors' contributions:}

All authors were involved in conceptualizing and writing up the manuscript. MM, ES and FCh were responsible for the study conceptualization, MM, EF, FCh and Kh, performed the data analysis and interpretation of data. MM, AGh were responsible for data collection. All authors read and approved the final manuscript.

\section{Acknowledgments}

I would like to extend my gratitude and appreciation to Vice-Chancellor for Research and Technology and all the people with SMI, their family, employers, supervisors, Healthcare teams, the Welfare Organization, the Imam Khomeini Relief Committee.

\section{References}

1. Arends I, Baer N, Miranda V, Prinz C, Singh S. Mental health and work: achieving well-integrated policies and service delivery. 2014.

2. Cancelliere C, Donovan J, Stochkendahl MJ, Biscardi M, Ammendolia C, Myburgh C, et al. Factors affecting return to work after injury or illness: best evidence synthesis of systematic reviews. Chiropractic \& Manual Therapies. 2016;24(1):32.

3. Coombes K, Haracz K, Robson E, James C. Pushing through: Mental health consumers' experiences of an individual placement and support employment programme. British Journal of Occupational Therapy. 2016;79(11):651-9.

4. Norder G, van der Ben CA, Roelen CAM, Heymans MW, van der Klink JJL, Bültmann U. Beyond return to work from sickness absence due to mental disorders: 5-year longitudinal study of employment status among production workers. European Journal of Public Health. 2017;27(1):79-83.

5. Killackey E, Allott K, Jackson HJ, Scutella R, Tseng YP, Borland J, et al. Individual placement and support for vocational recovery in first-episode psychosis: randomised controlled trial. The British journal of psychiatry : the journal of mental science. 2019;214(2):76-82. 
6. Kinoshita Y, Furukawa TA, Kinoshita K, Honyashiki M, Omori IM, Marshall M, et al. Supported employment for adults with severe mental illness. The Cochrane database of systematic reviews. 2013;2013(9):Cd008297.

7. Bejerholm U, Areberg C. Factors related to the return to work potential in persons with severe mental illness. Scandinavian journal of occupational therapy. 2014;21(4):277-86.

8. Poremski D, Chong SA, Subramaniam M. Helping People with Mental Illness Return to Employment: Challenging Existing Beliefs. Annals of the Academy of Medicine, Singapore. 2015;44(9):314-6.

9. Rassafiani M, Khalafbeige M, Mohammadi Shahboulaghi F, Haghgoo H-a, Taherkhani H. Families 'experiences to Find a Job for Relatives who Have Severe Mental Illness in Iran: A Qualitative Study. Function and Disability Journal. 2018;1(1):40-8.

10. Netterstrøm B, Eller NH, Borritz M. Prognostic Factors of Returning to Work after Sick Leave due to Work-Related Common Mental Disorders: A One- and Three-Year Follow-Up Study. BioMed research international. 2015;2015:596572.

11. Jetha A, Pransky G, Fish J, Hettinger LJ. Return-to-Work Within a Complex and Dynamic Organizational Work Disability System. Journal of Occupational Rehabilitation. 2016;26(3):276-85.

12. Noordik E, Nieuwenhuijsen K, Varekamp I, van der Klink JJ, van Dijk FJ. Exploring the return-to-work process for workers partially returned to work and partially on long-term sick leave due to common mental disorders: a qualitative study. Disability and rehabilitation. 2011;33(17-18):1625-35.

13. Shahabi S, Teymourlouy AA, Shabaninejad H, Kamali M, Lankarani KB, Mojgani P. Physical rehabilitation in Iran after international sanctions: explored findings from a qualitative study. Globalization and Health. 2020;16(1):86.

14. Ekbladh E, Thorell LH, Haglund L. Perceptions of the work environment among people with experience of long term sick leave. Work (Reading, Mass). 2010;35(2):125-36.

15. Holloway I, Galvin K. Qualitative research in nursing and healthcare: John Wiley \& Sons; 2016.

16. Schultz IZ, Gatchel RJ. Handbook of return to work: From research to practice: Springer; 2015.

17. Tucker W. Narratives of Recovery from Serious Mental Illness: Springer; 2016.

18. International Labour Organization. International Labour Standards country profile: Iran (Islamic Republic of Iran) [Internet,]. Genève: International Labour Organization; 2020 [Available from: https://www.ilo.org.

19. Holloway I, Wheeler S. Qualitative research in nursing and healthcare. 3rd ed ed. Chichester, U.K. ; Ames, lowa Blackwell Publishing; 2010.

20. Erlingsson C, Brysiewicz P. A hands-on guide to doing content analysis. African journal of emergency medicine : Revue africaine de la medecine d'urgence. 2017;7(3):93-9.

21. Guba EG, Lincoln YS. Competing paradigms in qualitative research. Handbook of qualitative research. 1994;2(163-194):105.

22. Habtamu K, Alem A, Hanlon C. Conceptualizing and contextualizing functioning in people with severe mental disorders in rural Ethiopia: a qualitative study. BMC psychiatry. 2015;15(1):34. 
23. Dunn EC, Wewiorski NJ, Rogers ES. A qualitative investigation of individual and contextual factors associated with vocational recovery among people with serious mental illness. American Journal of Orthopsychiatry. 2010;80(2):185.

24. Ebuenyi ID, Syurina EV, Bunders JFG, Regeer BJ. Barriers to and facilitators of employment for people with psychiatric disabilities in Africa: a scoping review. Global health action. 2018;11(1):1463658.

25. Holmlund L, Hultling C, Asaba E. Mapping Out One's Own Paths Toward Work: Focus on Experiences of Return to Work After Spinal Cord Injury. Qualitative health research. 2018;28(13):2020-32.

26. Hall T, Kakuma R, Palmer L, Minas H, Martins J, Kermode M. Social inclusion and exclusion of people with mental illness in Timor-Leste: a qualitative investigation with multiple stakeholders. BMC Public Health. 2019;19(1):702.

27. White C, Green RA, Ferguson S, Anderson SL, Howe C, Sun J, et al. The Influence of Social Support and Social Integration Factors on Return to Work Outcomes for Individuals with Work-Related Injuries: A Systematic Review. Journal of Occupational Rehabilitation. 2019;29(3):636-59.

28. Porter S, Lexén A, Johanson S, Bejerholm U. Critical factors for the return-to-work process among people with affective disorders: Voices from two vocational approaches. Work (Reading, Mass). 2018;60(2):221-34.

\section{Figures}

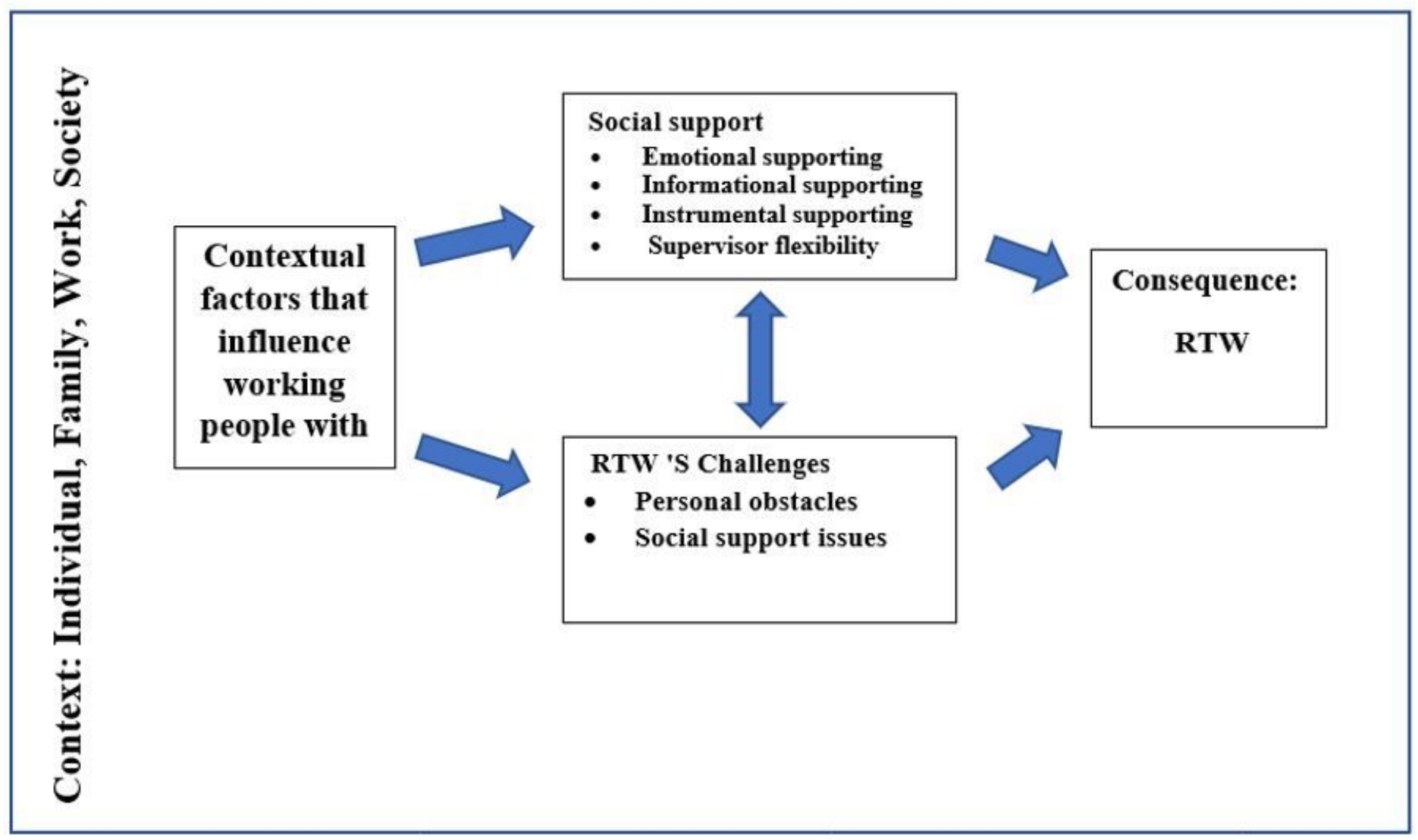




\section{Figure 1}

This shows that working people with SMI experience two facilitator and barrier factors for RTW, including social support and RTW's challenges in the context of the individual, family, work, and society. These two factors interact with each other.

\section{Supplementary Files}

This is a list of supplementary files associated with this preprint. Click to download.

- ReportingGuidelineChecklist.docx 